\title{
Weathering mass losses, plastic deformation and hydrologic evolution in a volcanic landscape.
}

\author{
L.A. DERRY AND O.A. CHADWICK ${ }^{123}$
}

${ }^{1}$ Cornell University \& Institut de Physique du Globe de Paris, lad9@cornell.edu

${ }^{2}$ University of California - Santa Barbara, ochadwick@ucsb.edu

Landscape level observations on Hawai' $i$ indicate that runoff ratios are essentially zero on the young active volcanic surfaces of Mauna Loa and Kilauea, and increase with age on Mauna Kea and Kohala surfaces. The transition from a landscape dominated by infiltration to one with stream dissection is a critical step in hydrologic and landscape development, and is correlated with the development of a weathered regolith. Under mesic conditions the time scale for formation of a substantial weathered regolith is $(O) 20$ ka. Mass losses estimated from immobile element ratios and porosity increase to ca. $20 \mathrm{ka}$, after which porosity and $K_{h}$ began to decrease, while the rate of mass loss slows. Extensive mass losses from the basalts preclude a model in which secondary mineral formation alone reduces permeability. Strain collapse of the soils is necessary to reduce hydraulic conductivity. We adapt a porous-plastic model of deformation (Gurson, 1977) to model the change in in surface hydrologic properties. Increased porosity and decreased material strength of the remaining matrix decrease the plastic limit of soil deformation. The yield stress of the residual material depends on the loss of networkforming silica, and can be parameterized from $\mathrm{H}_{2} \mathrm{O}$ content, Atterberg limits, $\mathrm{Ge} / \mathrm{Si}$ and $\mathrm{Si} / \mathrm{Nb}$ ratios. Coupled weathering and mechanical deformation appear capable of inducing a fundamental transformation in hydrologic and geomorphic processes in volcanic landscape. 